\title{
Clinical management of difficult to treat macroprolactinomas
}

\author{
Nicolas Sahakian ${ }^{\mathrm{a}}$, Frederic Castinettia, Henry Dufour ${ }^{\mathrm{b}}$, Thomas Graillon ${ }^{\mathrm{b}}$, Pauline Romanet ${ }^{\mathrm{c}}$, Anne Barlier, \\ Thierry Brue ${ }^{a}$ and Thomas Cuny ${ }^{\mathrm{a}}$

\begin{abstract}
aMarseille Medical Genetics, Inserm U1251, Hôpital de la Conception, Service d'Endocrinologie, Aix Marseille Univ, APHM, Marseille, France;

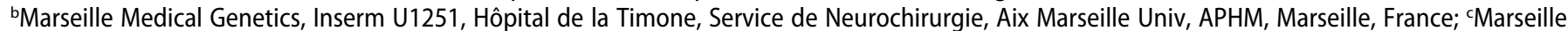
Medical Genetics, Inserm U1251, Hôpital de la Conception, Laboratoire de Biologie Moléculaire et Biochimie, Aix Marseille Univ, APHM, Marseille, France
\end{abstract}

\begin{abstract}
Introduction: Prolactinomas represent the most common pituitary adenomas encountered in the clinic. While a majority of these tumors will be successfully treated by dopamine agonist (DA) such as cabergoline, their management becomes problematic since a resistance to DA can occur and/or if the tumor displays features of aggressiveness, two conditions that are closely related.

Areas covered: Epidemiology and medical treatment of prolactinomas; resistance to DA and molecular basis of DA-resistance; therapeutical alternatives in case of DA-resistant Prolactinomas and therapies in development; summarizing conclusions.

Expert opinion: The management of DA-resistant prolactinomas requires a multidisciplinary approach by an expert team. Along with discussions about surgery with or without gamma knife radiosurgery, genetic screening for multiple endocrine neoplasia type 1 (MEN1) syndrome is actively discussed in a case-by-case approach. In case of surgery, a careful analysis of the tumor sample can provide information about its aggressivity potential according to recent criteria. Ultimately, temozolomide can be indicated if the tumor is rapidly growing and/or threatening for the patient.
\end{abstract}

\section{General considerations on prolactinomas}

Prolactinomas represent the most common hormone-secreting pituitary tumor encountered in the clinic with a prevalence of 100 per million of the population [1,2]. It currently accounts for $30-40 \%$ of all pituitary adenomas (PA) and, depending on their maximal diameter, they are commonly classified into microprolactinomas $(<10 \mathrm{~mm})$ or macroprolactinomas $(\geq 10 \mathrm{~mm})$. Histopathological data previously learned us that prolactin (PRL) can be secreted by several types of PiTNETs deriving either from lactotrophs, somatotrophs or mammosomatotrophs cells. Likewise, sparsely or densely granulated lactotroph tumors, acidophil stem cell tumors, poorly differentiated Pit1-lineage tumors can also lead to hyperprolactinemia. Therefore, in the following sections we will exclusively refer to the most common type of PRLsecreting PiTNETs, namely the one arising from lactotroph cells and called as Prolactinomas thereafter. Prolactinomas are overwhelmingly diagnosed in women population with a sex ratio estimated to be 10:1 before the fifth decade [3]. After this age, the frequency of Prolactinomas is the same in both gender, although macroprolactinomas are generally diagnosed at a later age in men as compared to women (median age incidence of 51 years in men vs. 34 to 42 years in women). In children and adolescents, PA is a rare pathological condition (less than $2 \%$ of all intracranial tumors) and prolactinomas represent about half of the PA phenotypes encountered in this population [4].

Because of their remarkable response-to-treatment, their slowgrowing behavior and their almost non-existent propensity to metastasize, Prolactinomas represent the archetype of benign tumors. In few cases however, they can present with stigmas of aggressivity represented by either invasion of perisellar structures (e.g. the cavernous sinus) and/or several relapse in spite of a wellconducted treatment. Accordingly, pathologists and clinicians adopted the terminology Pituitary Neuroendocrine Tumors (PiTNETs) instead of PA [5].

In exceptional cases, the primitive PRL-secreting tumor can be complicated by releasing of tumoral cells in the cerebrospinal fluid and/or distant metastasis in the central nervous system, two conditions that defined a PRL-secreting carcinoma [6].

The clinical symptoms and complains from patients diagnosed with microprolactinomas are usually the consequence of the hyperprolactinemia-induced gonadotroph deficiency, namely irregular menstruation or amenorrhea, decreased libido and erectile dysfunction. These symptoms reflect the inhibitory effect exerted by PRL on the reproductive axis by reducing both the secretion and pulsatility of gonadotropin-releasing hormone $(\mathrm{GnRH})$ neurons from the hypothalamus $[7,8]$. The latter effect could be mediated through inhibition of Kisspeptin neurons, which express PRL receptors and are major regulators of $\mathrm{GnRH}$ neurons $[9,10]$. The involvement of Kisspeptin neurons have been also demonstrated in both sexual and emotional functions which could, at least partially, explain the decreased libido observed in patients with hyperprolactinemia [11]. Besides irregular menstruations, PRL-secreting PiTNETs can cause galactorrhea and be associated 
with an increased risk of vertebral fractures in both men and women [12,13].

In macroprolactinomas, symptoms at the diagnosis include headaches, visual field impairment, symptoms related to anterior pituitary deficiencies and/or hyperprolactinemia [14].

Accordingly, the aim of the therapy in patients with macroprolactinomas is therefore twofold:

(1) to reduce and ideally normalize the serum PRL levels.

(2) to control the tumor volume, with recovery of the visual defect and/or pituitary functions when deficient.

The aim of this review is to summarize the current and recent therapeutical strategies to optimize the clinical management of difficult-to-treat macroprolactinomas.

\section{The medical treatment of prolactinomas}

In patients with Prolactinomas, we previously assumed that the aim of the therapy is to restore normal gonadal functions, fertility and to reduce tumor size [15]. DAs represent the cornerstone of the medical treatment and are always discussed as the first-line therapy in micro- as well in macroprolactinomas [16]. Their action is based on the property the lactotroph adenoma cells has to express high level of the dopamine receptor subtype 2 (D2DR) which, once binded by DA, led to the inhibition of both PRL secretion and cell proliferation [17]. Three DA are currently available, two that are ergot-derived compounds (i.e cabergoline and bromocriptine), and one, quinagolide, which is a non-ergotderived DA [18]. All of these DA are orally administered and their efficacy in the treatment of macroprolactinomas or in case of primary resistance to DA is briefly resumed in Table 1.

\subsection{Bromocriptine}

Bromocriptine (BRC) is the first DA which were used for the treatment of Prolactinomas as its prescription started at the end of the 80 's $[19,20]$. A posology ranging from $2.5 \mathrm{mg}$ to $15 \mathrm{mg}$ per day (median of $7.5 \mathrm{mg}$ per day) is commonly used but higher doses until 20 to $30 \mathrm{mg}$ per day can be required in almost a third of patients [21]. Results of a plethora of studies indicate that for microprolactinomas, BRC succeeds to normalize PRL levels, restores gonadal functions and decreases tumor mass in $80-90 \%$ of patients, while similar outcomes are found in $70 \%$ of patients with macroprolactinomas [21]. One of the major issues of BRC is the occurrence of adverse side effects, which can be observed in up to $10-12 \%$ of patients and mainly represented by digestive (nausea/vomiting, constipation, reflux, pain), neurological (headaches, dizziness, confusion, dyskinesia) and cardiovascular (postural hypotension, syncope) symptoms [22,23]. They generally occur after the initial dose and with dosage increases, but can be minimized by introducing the drug at a low dosage $(0.625$ or $1.25 \mathrm{mg} / \mathrm{d}$ ) at bedtime, by taking it with food, and by very gradual dose escalation [1]. BRC has been largely superseded by other DA with longer lasting effects and improved side effect profiles. Even its historical preferential use over others DA during pregnancy is now null [24].

\subsection{Cabergoline}

Cabergoline $(C A B)$ is a selective D2DR agonist which currently represents the most efficient DA as compared to BRC and quinagolide $[25,26]$. In a retrospective study assessing 455 cases of hyperprolactinemia, amongst who $41 \%$ and $42 \%$ were due to PRL-secreting micro- and macroadenomas, respectively, the PRL excess had been normalized in a total of $86 \%$ of cases under cabergoline treatment [27]. More specifically, the normalization of PRL level was obtained in $77 \%$ of patients with macroprolactinomas [27]. Similar results were observed in successive studies, which, in parallel, demonstrated that $C A B$ restored menses in $82 \%$ of women with amenorrhea [25], improved fertility by normalizing the sperm quality and sexual function in male [28] and eventually led to a significant tumor shrinkage in around 90\% of patients with Prolactinomas [29]. Male gender, invasive growth and giant tumors (i.e. diameter $>4 \mathrm{~cm}$ ) are associated with a lower response to cabergoline [30-32]. A starting posology of $0.5 \mathrm{mg} /$ week is common, including in cases of macroprolactinomas, as the antitumor effect observed with this compound can be both massive and rapid, as exemplified by the occurrence of chiasmal herniation (and visual field impairment) that have been described with low posologies of $C A B$ [33]. Similarly, cases of cerebrospinal fluid rhinorrhea were described in the weeks following the initiation of $C A B$ when the macroprolactinoma invaded the sphenoidal sinus [34]. If low doses of $C A B$ do not normalize hyperprolactinemia and if the patient tolerance is good, it is worthwhile to progressively increase the dose of the drug. As such, around $60 \%$ of patients with macroprolactinomas will achieve a normalization of their hyperprolactinemia under $C A B$ in an average delay of less than two years [35]. In a monocentric study, 44 patients (19.6\%) received CAB doses $>2 \mathrm{mg} /$ week with an average interval of 8 months between each dose increment, and a definitive $C A B$ resistance diagnosed in half of the patients ( 21 had a partial response to $C A B$ with decrease but no normalization of PRL level and 1 was unresponsive at all) [35]. Thus, increasing the dose of $C A B$ with periodical monitoring of both PRL levels and tumor volume seems reasonable over a period of 24 months, before stating that the tumor is resistant. Whether increasing the posology of $C A B$ can expose the patient to develop cardiac valvulopathy was still source of uncertainty. However, a recent study showed that for the posologies generally used in the treatment of 


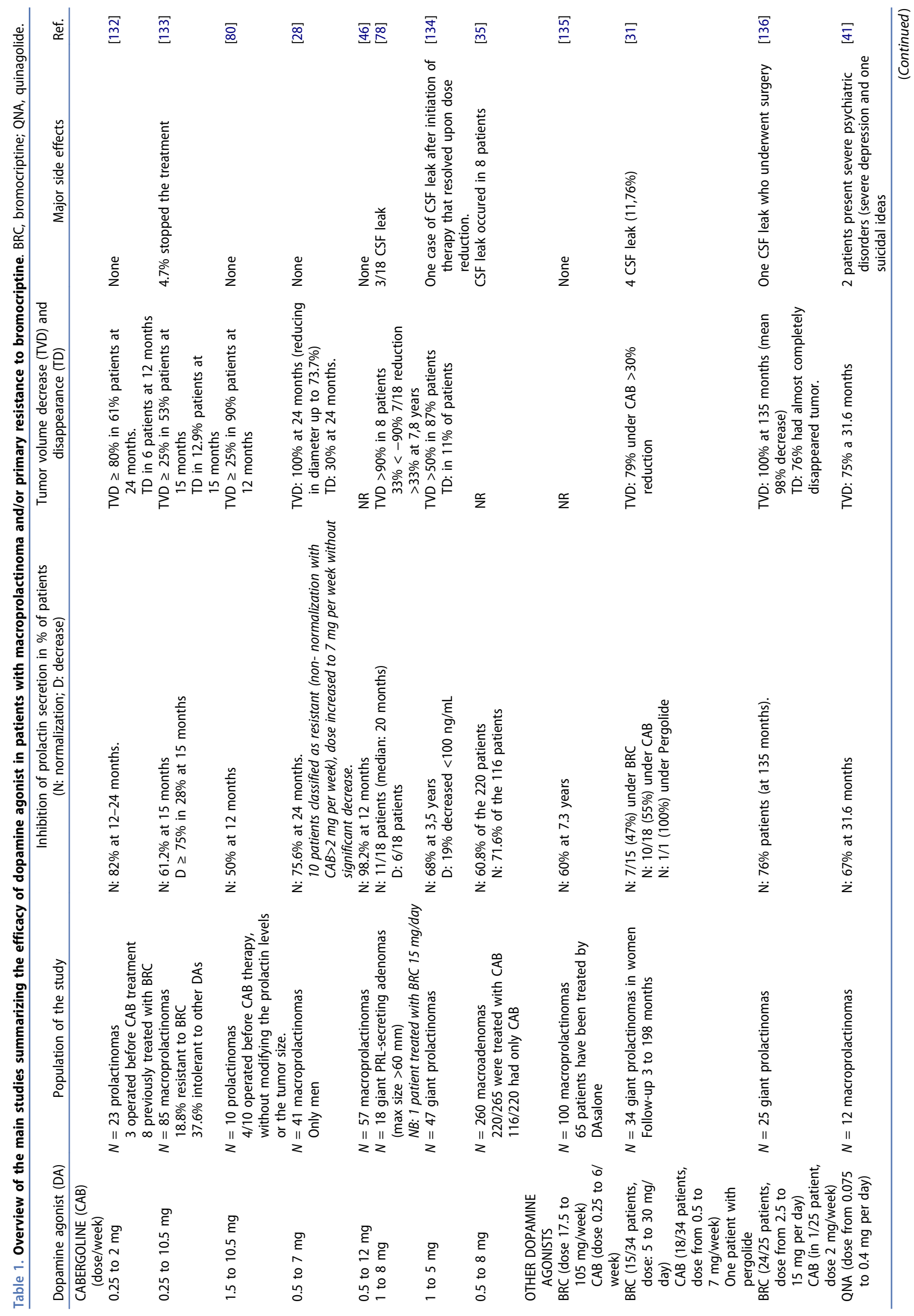




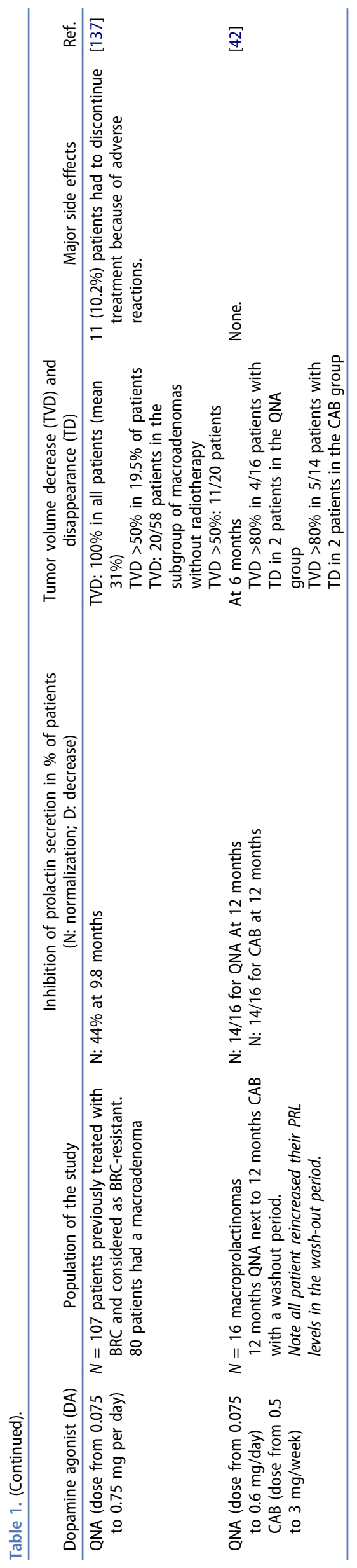

Prolactinomas, the use of $C A B$ was safe and did not overexpose the patient to the risk of valvulopathy [36].

In conclusion, $C A B$ is usually the first-line DA to be proposed with a side effects profile similar to those reported for the other DAs, but generally less frequent, less severe, and of shorter duration [37]. The only serious shortcoming currently under active investigation is the occurrence of a compulsive behavior in $5 \%$ of cases, such as excessive gambling and hypersexuality [38].

\subsection{Quinagolide}

Quinagolide (QNA) is a non-ergot-derived D2DR selective agonist which led, when administrated once-daily in patients with macroprolactinomas, to a significant reduction of tumor size and PRL levels in around $90 \%$ of patients and a further normalization of PRL level in 50\% of them [39-42]. It is usually administered at the average dose of 150 to $300 \mu \mathrm{g}$ per day. As compared to treatment with BRC, a greater reduction in nausea, vomiting, dizziness, and drowsiness during QNA administration is generally observed.

\subsection{Other dopamine agonists}

Pergolide is an ergot-derivated DA with long-acting D1 and D2 agonist properties, 100 times more potent than BRC allowing effective control of hyperprolactinemia with once-daily dose. However, it has been withdrawn from the market in 2007 because of cardiac valves adverse effects $[43,44]$

Lisuride is another ergot-derivated DA which was assessed for its ability to inhibit PRL secretion [21]. However, it never reaches the development to be used as a medical treatment in PRL-secreting adenomas. Finally, terguride, an analog of lisuride, can normalize PRL levels and reduce tumor size in a few number of patients with microprolactinomas, however it is currently not commercialized [20].

\section{Prolactinomas resistant to dopamine agonists}

The resistance-to-DA therapy represents the most challenging condition of difficult-to-treat macroprolactinomas. It systematically requires a multidisciplinary approach to optimize the care of the patient.

\subsection{Definition of the resistance}

The definition of resistance-to-DA still constitutes a source of uncertainty, and multiple definitions have been proposed in the literature. One, which is recurrent, defines the resistance as failure to achieve normal serum PRL levels under DA (commonly admitted $C A B \geq 2 \mathrm{mg} /$ week) or failure to reduce tumor size by at least $50 \%$ from the initial volume [45] (Figure 1). The cut-off of $2 \mathrm{mg} /$ week chosen on purpose for $C A B$ resistance actually makes sense. Indeed, in the group of patients treated with more than $\geq 2 \mathrm{mg} /$ week of $C A B$, only a third of them will normalize their PRL level under $3 \mathrm{mg} /$ week [46]. Therefore, the concept of resistance-to-DA does not mean per se that it is impossible to normalize PRL secretion but rather refers to a state in which the usual posologies of DAs do not achieve 

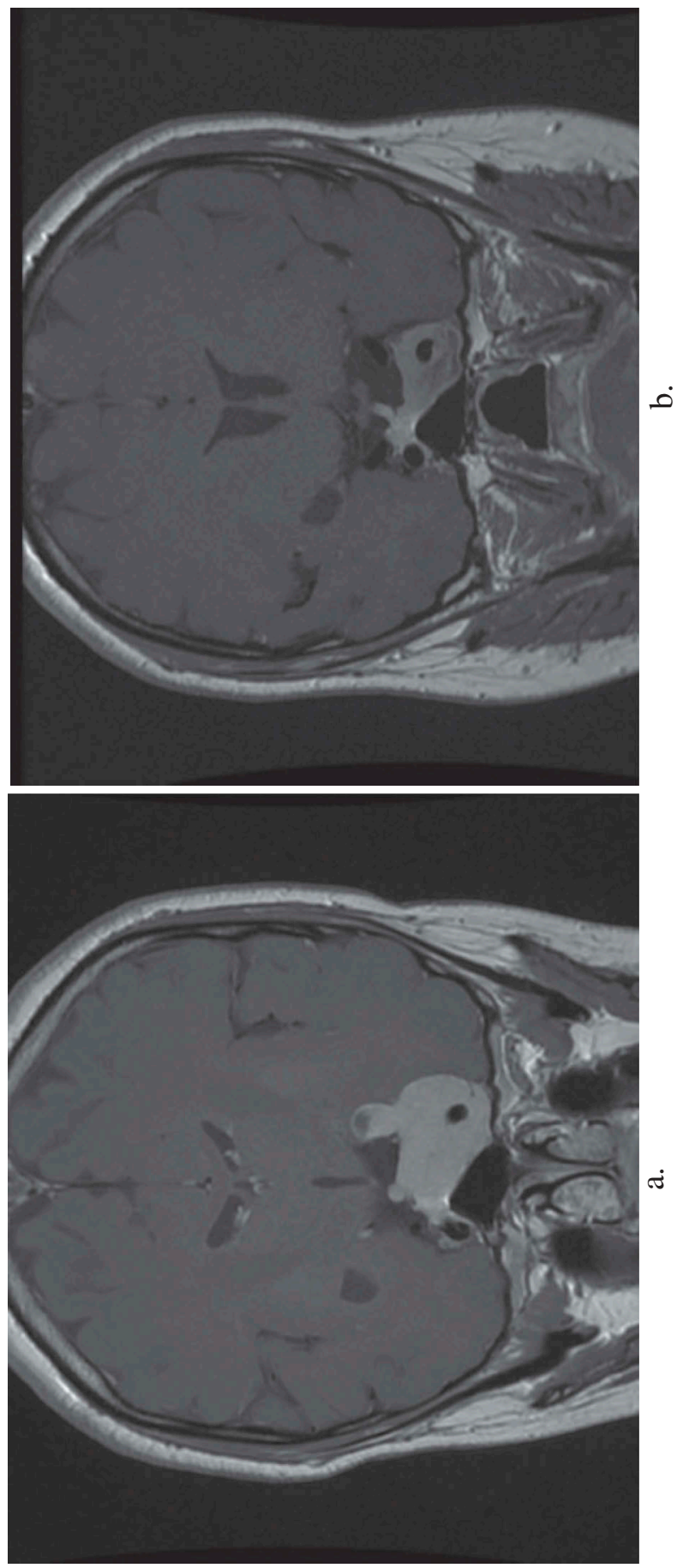

normalization of PRL levels or significant decrease of the tumor volume. According to these criteria, the prevalence of DAresistance in patients with Prolactinomas is 10 to $15 \%$ [47] .

\subsection{Molecular mechanisms underlying the resistance to $D A$}

\subsubsection{Alterations in the dopamine receptor subtype 2 (D2DR)}

Most of the studies that focused on the resistance-to-DA in Prolactinomas investigated the pattern of D2DR expression both at the mRNA and at the protein levels (Figure 2). Our group showed a significant decrease of the D2DR mRNA transcription and identified alterations in the D2DR-related signaling pathways of BRC-resistant human Prolactinomas, as compared to sensitive tumors [48-51]. More recently, the differential expression of D2DR isoforms was proposed as a putative molecular mechanism which leads to different response to DA. In the study conducted by Shimazu et al., patients with surgically resected Prolactinomas were divided, based on their response to DA, in responders $(n=5)$, resistants $(n=5)$ and secondary resistants to DA $(n=2)$. The authors found a significant decrease of the D2DR long isoform mRNA expression in resistant and secondary resistant tumors as compared to the sensitive ones [52]. In a similar approach, the correlation between the D2DR gene polymorphisms and the response to $C A B$ was studied in a series of 148 patients with Prolactinomas (among whom 29 males and 75 macroadenomas), however without significant results [53]. A trend for similar results was found in the study of Filopanti et al. where the allele frequencies (i.e. the Taql-A, Taql-B, Hphl and $N$ col alleles) of the four D2DR polymorphisms was compared between sensitive- and resistant-to-DA Prolactinomas, without any significant correlation eventually observed [54]. Nonetheless, in that study, a higher frequency of the Ncol-T allele was observed in resistant as compared to sensitive patients, which could suggest that this variant may lead to reduction of the expression and instability of the D2DR [54]. Recently, the wholeexome sequencing analysis of 12 human Prolactinomas (Six considered as responsive and six as resistant under a dose of $15 \mathrm{mg} /$ day of BRC, $11 / 12$ patients with macroprolactinomas) revealed a differential expression of the PRDM2 (PR domain zinc finger protein 2) gene, about five-fold lower in resistant tumors as compared to the responsive ones [55]. The PRDM2 gene encodes a protein whose major role is to stabilize chromosomal structures, mediates gene expression and ultimately plays a role of tumor suppressor gene [56]. In resistant-to-DA Prolactinomas, the expression level of the PRDM2 protein was also significantly decreased as compared to sensitive cases and its overexpression in the MMQ cells, a rat PRL-secreting pituitary tumor cell line, led to the upregulation of D2DR expression and potentiated the inhibitory effect of BRC over PRL secretion [55].

\subsubsection{The TGF beta pathway}

Amongst its multifunctional known roles as a cytokine, TGF beta (TGF- $\beta$ ) can also regulates the proliferation of lactotroph cells as well as their PRL secretion [57]. The TGF- $\beta$ signaling cascade is initiated by the binding of TGF- $\beta 1$, TGF- $\beta 2$, and TGF- $\beta 3$ ligands to the type II TGF- $\beta$ receptor (TGF- $\beta$ RII), followed by recruitment 


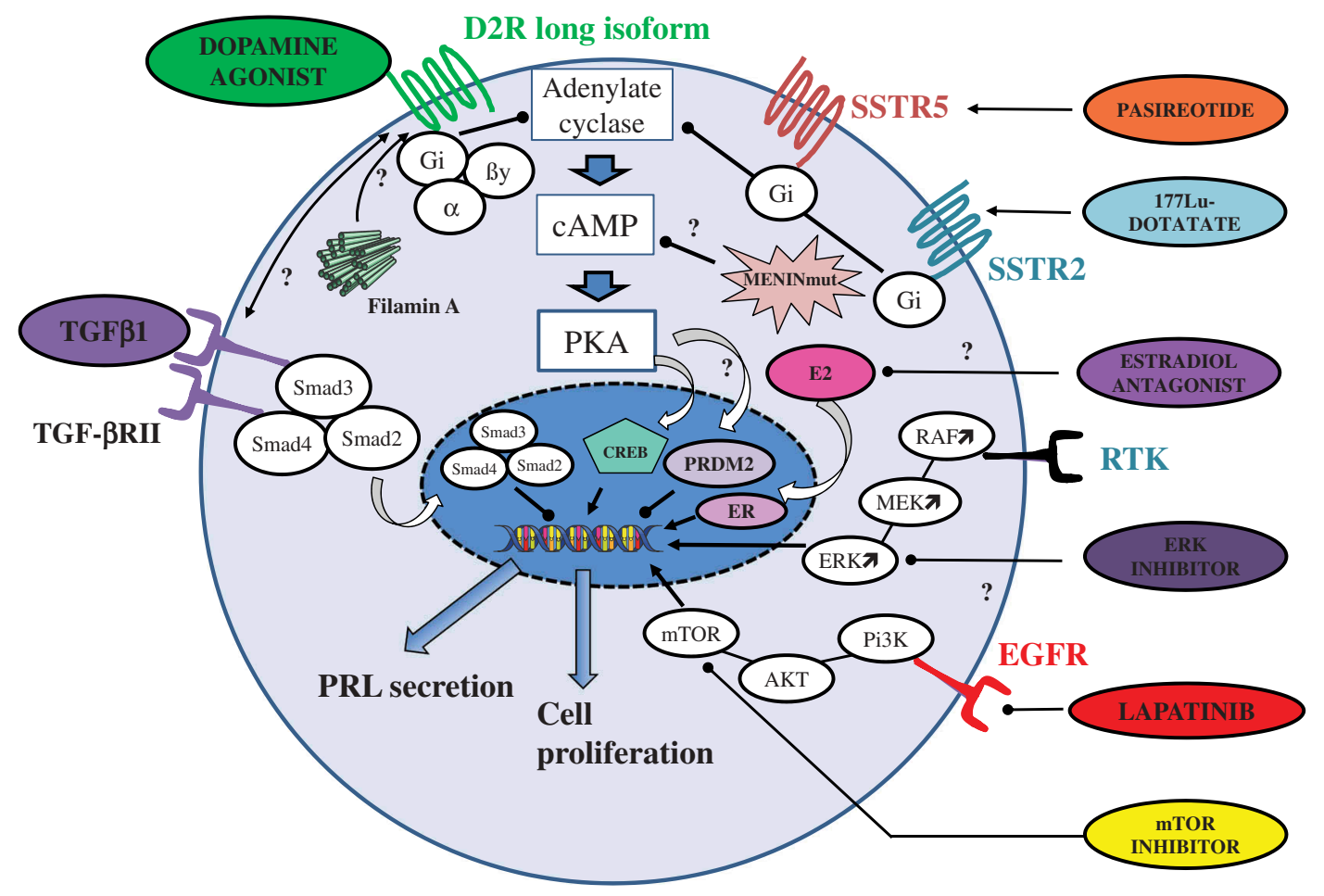

Figure 2. Schematic illustration of the main signaling pathways involved in the response to dopamine agonist therapy in pituitary lactotrophs. In the sake of clarity, major signaling pathways are simplified and readers can refer to the review for more details. On the right side of the cell, optional therapies and the ones that are in development are represented. The question mark means a possible effect supported by in vitro experiments.

and phosphorylation of the type I TGF- $\beta$ receptor (TGF- $\beta$ RI) to form a complex [58]. Once activated, TGF- $\beta$ RI triggers the formation of a heteromeric complex between Smad2, Smad3 and Smad4, which ultimately translocates into the nucleus to regulate expression of various transcription factors [59]. Sarkar et al. was the first to show that TGF- $\beta 1$ inhibits, in a similar manner than dopamine, both PRL secretion and proliferation of lactotrophs [60]. More recently, it was shown that, knocking out the D2DR expression or using a D2DR antagonist (sulpiride) resulted in the decrease of both TGF- $\beta 1$ secretion and TGF- $\beta$ RII expression by the lactotroph cells. These observations could suggest that the inhibiting effects of dopamine could be due, at least partially, to the TGF- $\beta$ system [61]. Interestingly, in a series of 12 patients who underwent surgery because of resistance to BRC (failure of PRL normalization after at least 3 months of $B R C \geq 15 \mathrm{mg} /$ day), a significant down-regulation of the TGF- $\beta$ / Smad signaling cascade assessed by high-content screening techniques (qRT-PCR, western blot, immunofluorescence and ELISA) was observed as compared to normal human anterior pituitaries [62]. However, a comparison with DA-sensitive tumors was unfortunately lacking in this work.

Because estradiol is known to increase PRL secretion and sustained lactotroph proliferation, a combined treatment with TGF- $\beta 1$ and fulvestrant, a selective estrogen receptor degrader, was tested in the rat GH3 somatolactotroph cell line. Of interest, a significant cytotoxicity in a dose- and time-dependent manner was observed with a simultaneous activation of Smad3 [62].
Overall, decreased TGF- $\beta 1$ activity and decreased expression of different components of the TGF- $\beta 1$ system have been described in animal models of Prolactinomas as well as in human Prolactinomas [57]. Taking into account that TGF $\beta 1$ inhibits lactotroph proliferation and PRL synthesis and secretion, recovering local TGF- $\beta 1$ activity may be one avenue worth exploring in case of DA-resistant Prolactinomas (Figure 2).

\subsubsection{Resistance-to-DA in the setting of genetic syndromes}

A condition that seems to be associated with a higher risk of resistance-to-DA is when the PRLoma developed in the setting of a multiple endocrine neoplasia type 1 (MEN1) syndrome. The latter is a genetic disease that predisposes carriers to development of various endocrine tumors including PiTNETs in $30-50 \%$ of patients [63]. Prolactinomas are the most frequent PiTNETs phenotype seen in MEN1 with $60 \%$ of cases. Moreover, MEN1-mutated (MEN1 mut) patients seem to be less responder to DA as compared to their non-mutated counterparts $[32,64]$. We are still lacking molecular explanations to decipher why and how MEN1 mutations lead to a lower sensitivity to DA; however, it is noteworthy to mention that histologically, MEN1mut Prolactinomas are more frequently invasive as compared to non-mutated Prolactinomas [64,65]. Evolution of Prolactinomas in MEN1mut patients are characterized by a younger age at onset, a more aggressive behavior as reflected by a higher 
propensity to invade surrounding structure and, in the scope of this review, a lower sensitivity to DA $[66,67]$.

Besides MEN1, Prolactinomas can also be developed in the setting of a Familial Isolated Pituitary Adenomas (FIPA) syndrome where they represent $10 \%$ of all tumor phenotypes and even 25\% when the Arylhydrocarbon Interacting Protein (AIP) gene is mutated [68]. In AIP-mutated Prolactinomas, $77 \%$ of patients were male with larger tumors, less sensitive to DA as compared to non-mutated patients [68].

\subsubsection{Other molecular pathways involved in DA-resistance} Several other molecular pathways have been incriminated in the occurrence of DA-resistance in Prolactinomas. For instance, the expression of Filamin-A, a cytoskeleton protein with scaffolding properties, is downregulated in parallel to the one of D2DR in human DA-resistant Prolactinomas [69]. Moreover, silencing the Filamin-A expression in human DA-sensitive Prolactinomas resulted in a significant decrease of D2DR membranous expression and abrogation of the DA-induced inhibition of PRL release and antiproliferative signals. In a reciprocal way, a restoration of the D2DR expression and PRL responsiveness to DA occurred when Filamin-A was overexpressed in DA-resistant Prolactinomas [69]. Besides Filamin-A, a recent study showed that low levels of PRB3 mRNA were observed in case of DAresistant Prolactinomas and exposed the patients to a higher risk of tumor recurrence [70]. However, the exact role of the PRB3 protein in Prolactinomas remains, to date, elusive.

\section{Therapeutical management of resistant-to-DA prolactinomas}

In the case of resistant-to-DA Prolactinomas, several options can be discussed; all of them being either proposed alone, combined and/or in a sequential approach. It includes switch to another DA, surgery, external radiotherapy, other-than-DA medical therapies or a watch-and-wait attitude.

\subsection{Switching to another dopamine agonist}

Since its commercialization, $C A B$ is usually preferred to BRC for the treatment of patients with Prolactinomas because of overall greater efficacy and tolerability. However, in certain regions of the world, BRC is still used as a first choice because of costs and/ or stock availabilities. Over the past years, CAB showed a greater efficacy as compared to BRC for the control of PRL oversecretion and has been successfully tested in patients considered as being resistant to $B R C[25,71-73]$. Low posology of CAB could, likewise, significantly overcome the resistance to QNA in Prolactinomas [74], a drug which is already effective in case of BRC resistance. However, this result could be overestimated because of better compliance and tolerance to CAB as compared to QNA, which actually induces a bias in the statistical analysis. In resistant-to$C A B$ patient, the most common medical approach is therefore to increase the dose of $C A B$, as long as a reduction in $P R L$ levels can be demonstrated with each stepwise increase $[35,75]$. Although it is unlikely that patient resistant to $C A B$ will demonstrate sensitivity to $B R C$, there is an existing clinical report of two patients resistant-to- $C A B$ with micro- and macroprolactinoma, respectively, who unexpectedly showed response to BRC [76].

\subsection{Surgical treatment of prolactinomas}

Before the development of DA, surgery was historically the treatment of choice for the cure of a PRLoma [1]. Currently, indications are mainly represented by cases of pituitary apoplexy, resistanceto-DA or by personal choice of the patient [77]. Even in cases of visual defect due to a macroprolactinoma, the standard of care favors the use of DAs as compared to surgery. The visual defect generally improves in the short term under DAs in a majority of patients, including those with giant (i.e. maximal diameter $\geq 4 \mathrm{~cm}$ ) Prolactinomas and in spite of a partial antitumoral effect [31,7880]. However, it should be noted that there is no dedicated studies which compared the outcome of the visual field defect in patients with macroprolactinoma when treated by DA as compared to patient treated in first-line by transphenoidal surgery. In highly trained hands, selective adenomectomy results in normalization of PRL levels in $75-90 \%$ of microprolactinomas. The multi-invasive nature of macroprolactinomas obviously affects the rate of cure obtained by purely surgical in such tumors which is achieved in around $40 \%$ of cases with recurrence rates of $20 \%$ over 10 years [81-83]. Surgery will provide the tumor histological characteristics, especially its pathological markers of aggressivity (Ki67 and P53 immunostaining, mitotic count). A recent retrospective study analyzed the surgical outcome of 184 men with surgically treated Prolactinomas. Among them, 178 patients had a macroprolactinoma (152 had a maximal size below $4 \mathrm{~cm}$ and 26 with a maximal size $>4 \mathrm{~cm}$ ) and $61 / 152(33.1 \%)$ of cases were invasive [84]. A post-surgical initial remission of PRL levels was observed in only $10 \%$ of invasive cases (i.e. suprasellar and/or parasellar and/or sphenoidal invasion) [84]. In case of resistance to DA, surgery is a valuable therapeutic option which results in normalization of PRL in half of patients [85]. In expert pituitary center, surgery for macroprolactinomas can be complicated by a diabetes insipidus in around $5 \%$ of cases, cerebro-spinal-fluid leak in $2-10 \%$ and anterior pituitary deficiencies in 1-15\%, respectively $[82,86]$.

\subsection{External radiotherapy}

External radiotherapy is usually discusses in patients who have clinically significant and symptomatic elevation of serum PRL in spite of DA therapy and/or transsphenoidal surgery (which means a third-line therapy in majority of cases). It can be proposed either as external beam radiation therapy (conformal radiotherapy) or stereotactic radiosurgery (SRS). Nowadays, the latter is preferably employed as its three dimensional approach is associated with a more rapid correction of hormone oversecretion and a lower risk of radiation-induced neoplasms and carotid stenosis [87]. Amongst SRS, gamma knife radiosurgery (GKRS) provides a highly conformal and selective therapeutic intervention in a single procedure performed with image guidance and using a multiheaded cobalt unit or a linear particle accelerator. On the opposite, the conformal radiotherapy is characterized by several fractions over the time (with generally daily administration). In Prolactinomas, previous studies, including one from our group, reported a mean rate of PRL normalization ranging from 26 to $43 \%$ with a time to remission comprised between 24 and 96 months [88-90]. In cases of resistance/intolerance-to-DA or invasive macroprolactinomas, a normalization of PRL level was obtained 
in half of 38 patients with a mean and median prescribed doses which were 21.3 and 25 Gy to the $50 \%$ isodose line, respectively. These doses are the most common used for GKRS in Prolactinomas [91]. Even if comparative studies with a significant number of patients are lacking, there are several lines of evidence which showed that withdrawal of DA therapy during SRS could be associated with better outcomes in terms of endocrine remission $[89,92]$. It is noteworthy to mention that cavernous sinus invasion was shown to be a significant negative prognosticator of endocrine remission [92]. Finally, after 40 months, radiotherapyinduced hypopituitarism occurred in $30 \%$ of cases.

Besides stereotactic radiotherapy, a conformal external radiotherapy can be discussed with the risk of adverse effects which is proportional to maximal dose and to fractionated dose per day. As compared to GKRS, conformal radiotherapy has two main drawbacks: the first one is the time to remission, equals to 5-10 years which is longer than that observed with the GKRS and therefore requires an effective medical treatment during this period of therapeutic latency. The second drawback of conformal radiotherapy is the risk of side effects, including hypopituitarism (in more than $80 \%$ of cases), optic neuritis, radiation-induced cerebral tumors, cerebral infraction and/or cognitive dysfunctions. These latter side effects occurred after a mean time of 10-20 years, and were not (at least not yet) described with the use of GKRS.

The antitumor efficacy (which means stabilization and/or decrease of the tumor residue) of radiotherapy in the setting of Prolactinomas is high, observed in 70 to $100 \%$ of cases over a delay ranging from 12 to 36 months $[89,93]$. This suggests that GKRS could be a valid alternative treatment in cases of intolerance or resistance-to-DA. Of note, median time to remission was usually 20 to 40 months, which means that gonadal steroid hormones administration can be necessary during this period [94].

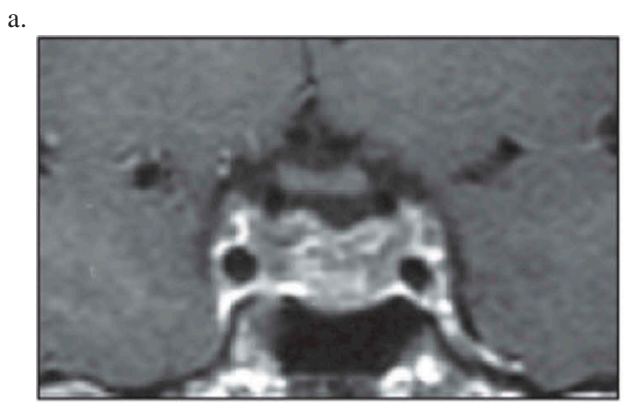

b.

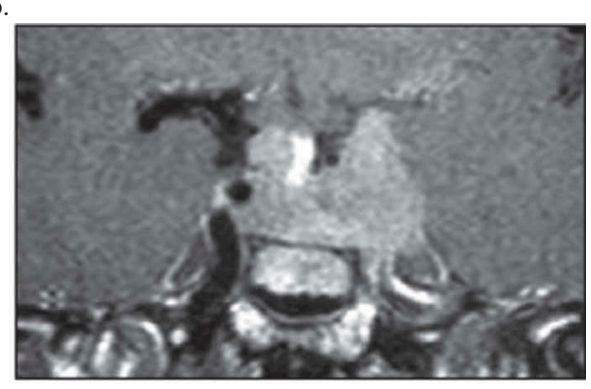

\subsection{Medical treatment of DA-resistant prolactinomas}

\subsubsection{Temozolomide}

In the setting of Prolactinomas, temozolomide (TMZ) never represents a first line treatment, however its indication can be actively discussed when the tumor is not controlled by the usual therapeutic regimen (DA, surgery, radiotherapy). Its efficacy was first demonstrated in glioblastomas before its successful use in advanced melanomas and neuroendocrine tumors [95]. TMZ is an alkylating chemotherapy, derivative of dacarbazine, with lipophilic properties allowing it to cross the blood-brain barrier and acts by inserting a methyl group to DNA bases (mainly guanine). By this way, it inhibits the gene transcription and cellular replication [96]. O(6)-methylguanine methyltransferase (MGMT) is an endogenous DNA repair enzyme that can remove this methyl group and thereby potentially counteracts the cytotoxic effect of TMZ. An inverse correlation has been shown between the degree of MGMT expression, due to silencing of the MGMT gene by methylation of its promoter, and the response to TMZ treatment in glioblastomas [97]. With $100 \%$ oral bioavailability, the standard regimen for administering $\mathrm{TMZ}$ consists in an oral daily dose of $150-200 \mathrm{mg} / \mathrm{m} 2$ body surface area for 5 days every 28 days. TMZ was proposed as a salvage therapy for the first time in 2006 to treat a PRL-secreting pituitary carcinoma [98] and subsequently tested in aggressive Prolactinomas [99]. In the latter and in PRLsecreting carcinomas, an overall control of tumor growth and PRL secretion under TMZ was observed in 66 and $73 \%$ of cases, respectively [100]. Moreover, patients carrying aggressive Prolactinomas who were responders to TMZ showed to have an improved overall survival as compared to their non-responders counterparts [101]. In our own experience, we previously reported a remarkable efficacy of the TMZ regimen in a patient with a MEN1 pituitary carcinoma (Figure 3) [102] .

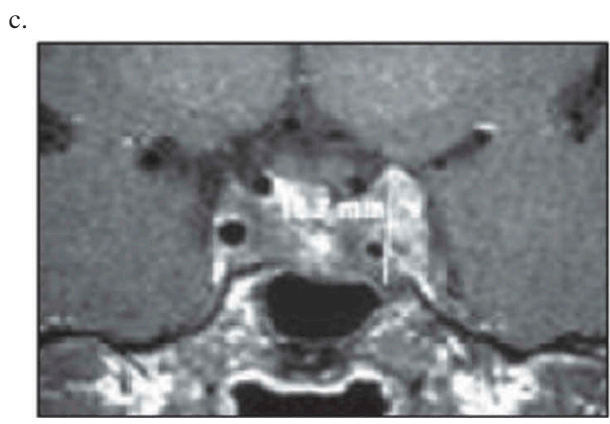

Figure 3. Coronal T1-weighted pituitary MRI in patient with a DA-resistant prolactinoma treated with temozolomide. [A] In 1995, after pituitary surgery, showing postoperative sequellae without any large visible residual adenomatous tissue. [B] In 2006, showing a relapse of the tumor with a large adenomatous residue in the left cavernous sinus. [C] In 2011, after 24 sessions of temozolomide (given between 2006 and 2008 ) with prolactin decreasing from 6950 to 98 ng/mL and the tumor volume from $62 \%$, at the last follow-up. 
In summary, TMZ is currently a suitable therapy that can be used as a first-line chemotherapy in case of aggressive and DA-resistant macroprolactinomas or pituitary carcinoma with tumor growth [103].

\subsubsection{Alternative medical therapies}

Other medical therapies can be discussed in a personalized approach when the PRL-secreting PiTNET displays signs of resistance to DAs. Somastostatinergic analogs (octreotide and lanreotide) which bind the somatostatin receptor subtype 2 (SSTR2) are generally inefficient to inhibit PRL secretion and/ or decrease the tumor volume [104]. Nonetheless, there are few clinical reports of DA-resistant Prolactinomas which showed that combination of octreotide plus $C A B$ could further inhibit both PRL secretion and tumor volume $[105,106]$. We previously hypothesized that a chimeric compound made of SSTR2 and D2DR moieties, called dopastatin, could further inhibit PRL secretion in SST2-overexpressing DA-resistant Prolactinomas. Unfortunately, the inhibitory effect observed with dopastatin was similar to the one obtained with $C A B$ [107]. Pasireotide (SOM230) is another somatostatin analog with high affinity for SSTR1, 2, 3 and 5. It is currently proposed in clinic for the treatment of acromegaly and Cushing's disease $[18,108]$. In vitro, SOM230 inhibits PRL secretion from primary culture of human PRL-secreting PiTNETs $[109,110]$ and was successfully tested in a patient with DA-resistant PRLoma [111]. In the latter, the tumor expressed high level of SSTR5, a condition which remains exceptional in DA-resistant Prolactinomas and explains why SOM230 is most of the time ineffective in such cases [104]. Finally, peptide receptor radionuclide therapy (PRRT) with 111 In-DTPA-octreotide has shown interesting result in a man with uncontrolled giant PRLoma resistant to conventional therapy [112] and could, in the era of the recent provision of 177Lu-DOTATATE (LUTHATERA ${ }^{\circledR}$ ) [113], represent an interesting treatment to discuss in specialized center.

Two recent cases of patients with BRC-resistant Prolactinomas suggest that metformine, an oral treatment commonly used in type 2 diabetes, can lead to normalization of PRL level when it is used in combination with BRC, and also to a subsequent decrease of the tumor volume after 24 months of treatment [114]. These results are supported in vitro by a synergistic inhibitory effect of metformine and BRC in combination over tumor growth and PRL secretion of xenograft models of lactotroph tumors [115].

\subsection{New therapeutical perspectives for DA-resistant prolactinomas}

\subsubsection{The EGF/EGFR system as a potential therapeutic} target

The epidermal growth factor (EGF) system comprises several transmembrane tyrosine kinase receptors known as EGFR (ErbB1, HER1), ErbB2 (HER2), ErbB3 (HER3) and ErbB4 (HER4) which, once binded by EGF, form either homo- and/or heterodimers, and activation of the intrinsic kinase domain and intracellular signaling [116]. EGFR is expressed in human Prolactinomas even though the pattern of EGFR expression in Prolactinomas seems to be heterogeneous and unconstant from one tumor to another [117-119]. In experimental models, gefitinib, an EGFR antagonist, decreased i/the cell proliferation of the rat somatolactotrope $\mathrm{GH} 3$ cell line ii/the PRL mRNA expression, iii/the PRL-secreting xenograft volume in rodents and the PRL secretion in vivo [120]. In humans, two patients with DA-resistant Prolactinomas were treated with lapatinib (1,250 mg daily for 6 months), a tyrosine kinase inhibitor of ErbB-1 and -2. One of them showed a significant improvement of his PRL level (from 311 to $67 \mathrm{ng} / \mathrm{ml}$ ) together with a regression of the central portion of the tumor mass, albeit incomplete. In the second patient, lapatinib was moderately effective with a decrease of PRL level from 447 to $259 \mathrm{ng} / \mathrm{mL}$ (at the last follow-up) however without any shrinkage of the tumor mass [118].

\subsubsection{The RAF/MEK/ERK and PI3K/AKT/MTOR signaling pathways in prolactinomas}

The RAF/MEK/ERK and PI3K/AKT/mTOR signaling pathways are crucial to many aspects of cell growth and survival, in physiological as well as in pathological conditions [121]. Previously, no differences were found between PA and normal pituitary samples in the expression of phosphorylated/total mTOR, TSC2 or p70S6K known to be the downstream effectors of the PI3K/AKT signaling pathway [122]. As such, the PI3K/AKT/ mTOR signaling pathway does not seem to represent a canonical pathway involved in the pathogenesis of PA, especially Prolactinomas. On the opposite, the expression of the phosphorylated forms of MEK1/2 and ERK1/2, the downstream effectors of the MAPK signaling pathway, was significantly higher in Prolactinomas as compared to normal pituitaries [122]. Interestingly, a recent study suggests an intricate cross-talk between the ERK and PI3K signaling pathways in a rat somatolactotrope cell line GH4T2, in which PI3K appears as a counterregulatory mediator of the ERK-induced PRL transcription [123]. In the same cell line, the inhibition effect obtained with $C A B$ over PRL secretion and cell proliferation was mediated through the phosphorylation of $\mathrm{S} 6 \mathrm{~K}$, a target of mTOR which therefore seems to be closely involved in the response to DA in Prolactinomas. Besides the response to DA, the mTOR signaling pathway was recently identified as a promotor of pituitary tumor development, more specifically in Prolactinomas [124] and in vitro data suggest that rapamycin, a mTOR inhibitor, could be effective in the treatment of lactotroph tumoral cells [125]. Recently, a patient with DAresistant PRLoma was successfully with everolimus, a mTOR inhibitor, with a significant decrease of both PRL levels and tumor volume after 5 months [126]. The tumor immunohistochemical analysis of this patient revealed high level of p-AKT, p4EBP1 and p70S6K [126]. In conclusion, pharmacological inhibitors of the ERK or PI3K pathways could constitute an interesting therapeutic approach in DA-resistant Prolactinomas.

\section{Summarizing conclusions}

In conclusion, Prolactinomas represent the most common hormone-secreting pituitary tumor with an overrepresentation of microadenomas in the population of young women. Difficult-to-treat Prolactinomas are represented by 
Prolactinomas that are resistant to DA therapy a condition which is correlated to the occurrence of a macroadenoma in more than $80 \%$ of cases [47]. Because these tumors can be roughly assimilated to aggressive tumors, a multidisciplinary team meeting is obviously required to guide the best therapeutical approach to propose [103].

The above manuscript gives an overview of the valuable treatments to discuss when the patient does not respond (enough) to DA. In clinical practice, two situations can be distinguished. First presentation (which is the more frequent): the patient keeps a significant oversecretion of PRL after surgery, as it occurs in $60 \%$ of macroadenomas [85,127] but the tumor does not display features of aggressivity on the pathological analysis and does not exert a tumor mass effect on surrounding structures. The concern is mainly related to the effect of hyperprolactinemia, especially hypogonadism. A step-by-step therapeutic approach is generally adopted with increasing the dose of $C A B$, and potentially a subsequent radiotherapy. In the meanwhile, an hormonal substitution can be necessary with periodical follow up by pituitary MRI. It is important to underline that the risk of cardiac valvulopathy while increasing the dose of $C A B$ is rare. In our daily practice, we recommend, as others do, to perform one echocardiography at baseline, which, if normal, will require a subsequent control in the future if the patient has an audible murmur, if he is treated for more than 5 years at a dose of more than $3 \mathrm{mg}$ per week, or for those who maintain $C A B$ treatment after the age of 50 years [128]. When the tumor is aggressive according to Trouillas criteria [129], the concern is rather related to its (uncontrolled) invasive behavior and requires urgent therapeutic management. Repeated surgery, MGMT immunostaining and ultimately TMZ can be proposed with a close monitoring. Once PRL is normalized, and as long as it remains normal or stable overtime, the likelihood of a significant tumor growth remains low, and we therefore assume that repeated pituitary MRI in the follow up are unnecessary [130].

In summary, different therapeutic modalities are discussed during the care of a patient with a DA-resistant macroprolactinoma. Selected therapeutic perspectives have been discussed and detailed in this review, but many others are in the pipeline and could be of interest in PRL-secreting PiTNETs. This is the case for the immunotherapy whose pharmalogical action rather targets the microenvironment than the tumor niche itself. A spectacular antitumoral effect of the combination of ipilimumab (anti-CTLA4) and nivolumab (Anti-PD1), was observed in a case of ACTH-secreting pituitary carcinoma [131]. The impact of the immune components in the pathogenesis, behavior and response-to-treatment of Prolactinomas remains largely unknown. Therefore, a better understanding of the molecular and cellular factors underlying the resistance to DA in Prolactinomas could allow in the future to personnalize the treatment for a patient and optimize his medical care.

\section{Expert opinion}

Dopamine agonist (DA) treatment represents the first-line therapy for Prolactinomas either micro- or macroadenomas and as such, their overall efficacy is one of the most remarkable observed in the field of medicine. Even when a single weekly dose of $C A B$ is unsufficient, it is worth a try to increase the posology given the fact that a certain proportion of macroprolactinomas will respond at higher than conventional dose. Based on our experience, some clinical indicators are, from the moment of the diagnosis, are already highly predictive of resistance to DA: a (really) young age (i.e. $<18$ years old) at diagnosis, the existence of a MEN1 or less frequently AIP germline mutation, and a giant adenoma (which means maximal diameter exceeding $4 \mathrm{~cm}$ ). In the latter situation, a tumor mass effect usually occurs on the optic chiasm, likely responsible of visual field defect. The authors want to underline that $C A B$ therapy, even when a state of resistance is observed with no reduction of the tumor volume, a dramatic improvement of the visual field can be observed, suggesting that the treatment with $C A B$ can modify the consistency of the tumor making it more soft. This hypothesis is also supported by the possible occurrence of intratumoral hemorrhage during the treatment with $C A B$.

We usually recommend a careful assessment of the DA efficacy on both PRL secretion and tumor volume reduction by MRI, 4 months after initiation of the therapy and then 6 to 8 months later.

As such, we recommend to wait for 12 months of treatment under $C A B$ before considering the tumor is resistant to DA.

The different works that have been published so far to decipher the molecular abnormalities involved in the resistance to DA in Prolactinomas have sparked many interest for the pharmacological research however without concrete clinical applications yet. Indeed, in the case of treating DA-resistant tumor (debulking) surgery is the prior therapeutic option more or less followed by stereotactic radiotherapy on the tumor residue. This therapeutical strategy at least offers to the clinician the access to the tumor histopathology and especially to its aggressive behavior. This last point is important in case of multiple relapse and uncontrolled growth of the tumor which therefore could indicate treatment with TMZ. The results obtained on tumoral residue with gamma knife radiosurgery (GKRS) are encouraging in a majority of patients when performed in an expert center, with few side effects and a prolonged control of the tumor volume and hormonal secretion. The current alternative therapies to dopamine agonist are almost nonexistent and only few ones have shown an interesting effect in case reports. This is the case with somatostatin analogs including pasireotide, whose use could be attempted when the tumor expressed high levels of somatostatin receptor subtype 5 . Similarly, the use of Lapatinib could be of interest but its efficacy has been demonstrated in very few cases of resistant Prolactinomas. Overall therapies directed toward membrane receptors do not appear to us as the preferential targets to develop in case of DA-resistant or only in a cotargeting therapeutical approach. On the opposite, promising approach are represented by inhibitors of canonical signaling pathways situated downstream the transmembrane receptors (e.g. MAPK) as well as the development of epigenetic drugs that could lead to the re-expression of D2DR when this one is down-regulated.

A subgroup of patient will present with a tumor residue of their DA-resistant Prolactinomas however without significant 
progression. As long as the tumor does not lead to tumoral and/or hormonal symptoms, a regular follow-up can be sufficient in the management of such patients. In all the remaining cases (i.e. when a significant progression is observed over the time) a multidisciplinary approach is of upmost importance to discuss which therapeutical strategy presents the best risk/ benefit balance for the patient in regards to his/her clinical profile.

We, and others, assume that the therapeutical management of difficult to-treat macroprolactinomas will benefit, instead of increasing the posology of DA, from identification of new therapeutical targets in case of DA-resistance. As such, the recent works conducted by the group of Melmed investigated drugs directed against the Erb receptor as a reliable treatment to consider. Likewise, it is worth trying to assess the efficacy of pasireotide in tumors expressing significant level of somatostatin receptor subtype 5 . Finally the coming years will probably also marked by new stereotactic radiosurgery procedures that will undoubtedly optimize the treatment of PRLoma residues.

\section{References}

Papers of special note have been highlighted as either of interest $(\cdot)$ or of considerable interest (..) to readers.

1. Gillam MP, Molitch ME, Lombardi G, et al. Advances in the treatment of prolactinomas. Endocr Rev. 2006;27:485-534.

2. Colao A. The prolactinoma. Best Pract Res Clin Endocrinol Metab. 2009;23:575-596.

3. Gruppetta M, Mercieca C, Vassallo J. Prevalence and incidence of pituitary adenomas: a population based study in Malta. Pituitary. 2013;16:545-553.

4. Ciccarelli A, Daly AF, Beckers A. The epidemiology of prolactinomas. Pituitary. 2005;8:3-6.

5. Asa SL, Casar-Borota O, Chanson P, et al. From pituitary adenoma to pituitary neuroendocrine tumor (PitNET): an international pituitary pathology club proposal. Endocr Relat Cancer. Internet]. 2017 [cited 2019 Jan 21];24:C5-C8. Available from: http://www.ncbi.nlm. nih.gov/pubmed/28264912

- The first paper dealing with the new denomination of Pituitary Neuroendocrine Tumors.

6. Heaney AP. Pituitary carcinoma: difficult diagnosis and treatment. J Clin Endocrinol Metab. 2011;96:3649-3660.

7. Abbara A, Clarke SA, Nesbitt A, et al. Interpretation of serum gonadotropin levels in hyperprolactinaemia. Neuroendocrinology. Internet]. 2018 [cited 2019 Jan 7];107:105-113. Available from: http://www.ncbi.nlm.nih.gov/pubmed/29660734
8. Page-Wilson G, Smith PC, Welt CK. prolactin suppresses GnRH but not TSH secretion. Horm Res Paediatr. Internet]. 2006 [cited 2019 Jan 7];65:31-38. Available from: http://www.ncbi.nlm.nih.gov/ pubmed/16357488

9. Sonigo C, Bouilly J, Carré N, et al. Hyperprolactinemia-induced ovarian acyclicity is reversed by kisspeptin administration. J Clin Invest. Internet]. 2012 [cited 2019 Jan 7];122:3791-3795. Available from: http://www.ncbi.nlm.nih.gov/pubmed/23006326

10. Kaiser UB. Hyperprolactinemia and infertility: new insights. J Clin Invest. Internet]. 2012 [cited 2019 Jan 7];122:3467-3468. Available from: http://www.ncbi.nlm.nih.gov/pubmed/23193578

11. Comninos AN, Demetriou L, Wall MB, et al. Modulations of human resting brain connectivity by kisspeptin enhance sexual and emotional functions. JCI Insight. Internet]. 2018 [cited 2019 Jan 7];3. Available from: http://www.ncbi.nlm.nih.gov/pubmed/30333302

- An original paper describing the complex network of kisspeptin neurons and their role in sexual behavior.

12. Mazziotti G, Porcelli T, Mormando M, et al. Vertebral fractures in males with prolactinoma. Endocrine. Internet]. 2011 [cited 2019 Jan 21];39:288-293. Available from: http://www.ncbi.nlm.nih.gov/ pubmed/21479837

13. Mazziotti G, Mancini T, Mormando $M$, et al. High prevalence of radiological vertebral fractures in women with prolactin-secreting pituitary adenomas. Pituitary. Internet]. 2011 [cited 2019 Jan 21];14:299-306. Available from: http://www.ncbi.nlm.nih.gov/ pubmed/21301967

14. Tirosh A, Benbassat C, Lifshitz A, et al. Hypopituitarism patterns and prevalence among men with macroprolactinomas. Pituitary. 2015;18:108-115.

15. Molitch ME. Diagnosis and treatment of pituitary adenomas. JAMA. 2017;317:516.

- $A$ recent and comprehensive review about the management of Pituitary Adenomas.

16. Tirosh A, Shimon I. Management of macroprolactinomas. Clin Diabetes Endocrinol. 2015;1:5.

17. Ben-Jonathan N, Hnasko R. Dopamine as a prolactin (PRL) inhibitor. Endocr Rev. 2001;22:724-763.

18. Cuny T, Barlier A, Feelders R, et al. Medical therapies in pituitary adenomas: current rationale for the use and future perspectives. Ann Endocrinol (Paris). 2015;76:76.

19. Molitch ME, Elton RL, Blackwell RE, et al. Bromocriptine as primary therapy for prolactin-secreting macroadenomas: results of a prospective multicenter study. J Clin Endocrinol Metab. Internet]. 1985 [cited 2018 Nov 4];60:698-705. Available from: https://academic.oup.com/jcem/article-lookup/doi/10.1210/jcem60-4-698

20. Dallabonzana D, Liuzzi A, Oppizzi G, et al. Chronic treatment of pathological hyperprolactinemia and acromegaly with the new ergot derivative terguride. J Clin Endocrinol Metab. 1986;63:1002-1007.

21. Colao A, Savastano S. Medical treatment of prolactinomas. Nat Rev Endocrinol. 2011;7:267-278.

22. Wong A, Eloy JA, Couldwell WT, et al. Update on prolactinomas. Part 2: treatment and management strategies. J Clin Neurosci. 2015;22:1568-1574.

23. Kissner DG, Jarrett JC. Side effects of bromocriptine. N Engl J Med. Internet]. [cited 2018 Nov 4];302:749-750. Available from: http:// www.nejm.org/doi/abs/10.1056/NEJM198003273021313

24. Molitch ME. Endocrinology in pregnancy: management of the pregnant patient with a prolactinoma. Eur J Endocrinol. Internet]. 2015 [cited 2018 Nov 4];172:R205-R213. Available from: http:// www.ncbi.nlm.nih.gov/pubmed/25805896

25. Webster J, Piscitelli G, Polli A, et al. A comparison of cabergoline and bromocriptine in the treatment of hyperprolactinemic amenorrhea. cabergoline comparative study group. $N$ Engl J Med. 1994;331:904-909.

- First study comparing the efficacy of bromocriptine and cabergoline in a randomized trial.

26. Colao A, Di Sarno A, Guerra E, et al. Drug insight: cabergoline and bromocriptine in the treatment of hyperprolactinemia in men and women. Nat Clin Pract Endocrinol Metab. 2006;2:200-210. 
27. Verhelst J, Abs R, Maiter $D$, et al. Cabergoline in the treatment of hyperprolactinemia: a study in 455 patients. J Clin Endocrinol Metab. 1999;84:2518-2522.

28. Colao A, Vitale G, Cappabianca P, et al. Outcome of cabergoline treatment in men with prolactinoma: effects of a 24-month treatment on prolactin levels, tumor mass, recovery of pituitary function, and semen analysis. J Clin Endocrinol Metab. 2004;89:1704-1711.

29. Colao A, Di Sarno A, Landi ML, et al. macroprolactinoma shrinkage during cabergoline treatment is greater in naive patients than in patients pretreated with other dopamine agonists: a prospective study in 110 patients. J Clin Endocrinol Metab. Internet]. 2000 [cited 2018 Sep 4];85:2247-2252. Available from: http://www.ncbi. nlm.nih.gov/pubmed/10852458

30. Delgrange E, Daems T, Verhelst J, et al. Characterization of resistance to the prolactin-lowering effects of cabergoline in macroprolactinomas: a study in 122 patients. Eur J Endocrinol. 2009;160:747-752.

31. Delgrange $E$, Raverot $G$, Bex $M$, et al. Giant prolactinomas in women. Eur J Endocrinol. Internet]. 2014;170:31-38. Available from: https://eje.bioscientifica.com/view/journals/eje/170/1/31.xml

32. Salenave $S$, Ancelle $D$, Bahougne $T$, et al. Macroprolactinomas in children and adolescents: factors associated with the response to treatment in 77 patients. J Clin Endocrinol Metab. 2015;100:1177-1186.

33. Raverot G, Jacob M, Jouanneau E, et al. Secondary deterioration of visual field during cabergoline treatment for macroprolactinoma. Clin Endocrinol (Oxf). Internet]. 2009 [cited 2019 Jan 7];70:588-592. Available from: http://www.ncbi.nlm.nih.gov/pubmed/18673461

34. Netea-Maier RT, van Lindert EJ, Timmers H, et al. Cerebrospinal fluid leakage as complication of treatment with cabergoline for macroprolactinomas. J Endocrinol Invest. Internet]. 2006 [cited 2018 Nov 4];29:1001-1005. Available from: http://www.ncbi.nlm. nih.gov/pubmed/17259798

35. Paepegaey A-C, Salenave S, Kamenicky P, et al. Cabergoline tapering is almost always successful in patients with macroprolactinomas. J Endocr Soc. 2017;1:221-230.

36. Vroonen L, Lancellotti P, Garcia MT, et al. Prospective, long-term study of the effect of cabergoline on valvular status in patients with prolactinoma and idiopathic hyperprolactinemia. Endocrine. 2017;55:239-245.

37. Melmed S, Casanueva FF, Hoffman AR, et al. Diagnosis and treatment of hyperprolactinemia: an endocrine society clinical practice guideline. J Clin Endocrinol Metab. Internet]. 2011 [cited 2018 Nov 5];96:273-288. Available from: http://www.ncbi.nlm.nih.gov/ pubmed/21296991

-. Recommendations of the Endocrine Society on treatment and management of hyperprolactinemia.

38. Noronha S, Stokes V, Karavitaki N, et al. Treating prolactinomas with dopamine agonists: always worth the gamble? Endocrine. 2016;51:205-210.

39. Van't Verlaat JW, Croughs RJ, Brownell J. Treatment of macroprolactinomas with a new non-ergot, long-acting dopaminergic drug, CV 205-502. Clin Endocrinol (Oxf). Internet]. 1990 [cited 2019 Jan 21];33:619-624. Available from: http://www.ncbi.nlm.nih.gov/ pubmed/1979262

40. Kvistborg A, Halse J, Bakke S, et al. Long-term treatment of macroprolactinomas with CV 205-502. Acta Endocrinol (Copenh). Internet]. [cited 2019 Jan 21];128:301-307. Available from: http:// www.ncbi.nlm.nih.gov/pubmed/8098891

41. Schultz PN, Ginsberg L, McCutcheon IE, et al. Quinagolide in the management of prolactinoma. Pituitary. 2000;3:239-249.

42. Di Sarno A, Landi ML, Marzullo $P$, et al. The effect of quinagolide and cabergoline, two selective dopamine receptor type 2 agonists, in the treatment of prolactinomas. Clin Endocrinol (Oxf). 2000;53:53-60.

43. Schade R, Andersohn F, Suissa S, et al. Dopamine agonists and the risk of cardiac-valve regurgitation. N Engl J Med. 2007;356:29-38.

44. Zanettini R, Antonini A, Gatto G, et al. Valvular heart disease and the use of dopamine agonists for Parkinson's disease. N Engl J Med. 2007;356:39-46.

45. Molitch ME. Management of medically refractory prolactinoma. J Neurooncol. Internet]. 2014 [cited 2018 Nov 4];117:421-428. Available from: http://www.ncbi.nlm.nih.gov/pubmed/24146188
46. Ono M, Miki N, Kawamata T, et al. Prospective study of high-dose cabergoline treatment of prolactinomas in 150 patients. J Clin Endocrinol Metab. Internet]. 2008 [cited 2018 Nov 5];93:4721-4727. Available from: https://academic.oup.com/jcem/ article-lookup/doi/10.1210/jc.2007-2758

47. Vroonen L, Jaffrain-Rea M-L, Petrossians $P$, et al. Prolactinomas resistant to standard doses of cabergoline: a multicenter study of 92 patients. Eur J Endocrinol. 2012;167:651-662.

- A retrospective study which characterize prolactinomas resistant to dopamine agonist.

48. Pellegrini I, Rasolonjanahary R, Gunz G, et al. Resistance to bromocriptine in prolactinomas. J Clin Endocrinol Metab. 1989;69:500-509.

49. Pellegrini I, Costa R, Grisoli F, et al. Abnormal dopamine sensitivity in some human prolactinomas. Horm Res. 1989;31:19-23.

50. Caccavelli L, Feron F, Morange I, et al. Decreased expression of the two $D_{2}$ dopamine receptor isoforms in bromocriptine-resistant prolactinomas. Neuroendocrinology. 1994;60:314-322.

51. Caccavelli L, Morange-Ramos I, Kordon C, et al. Alteration of $G$ alpha subunits mRNA levels in bromocriptine resistant prolactinomas. J Neuroendocrinol. 1996;8:737-746.

52. Shimazu S, Shimatsu A, Yamada S, et al. Resistance to dopamine agonists in prolactinoma is correlated with reduction of dopamine D2 receptor long isoform mRNA levels. Eur J Endocrinol. 2012;166:383-390.

53. Bueno C, Trarbach E, Bronstein $M$, et al. Cabergoline and prolactinomas: lack of association between DRD2 polymorphisms and response to treatment. Pituitary. 2017;20:295-300.

54. Filopanti M, Barbieri AM, Angioni AR, et al. Dopamine D2 receptor gene polymorphisms and response to cabergoline therapy in patients with prolactin-secreting pituitary adenomas. Pharmacogenomics J. 2008;8:357-363.

55. Gao H, Wang F, Lan X, et al. Lower PRDM2 expression is associated with dopamine-agonist resistance and tumor recurrence in prolactinomas. BMC Cancer. 2015;15:15.

56. Cheedipudi S, Puri D, Saleh A, et al. A fine balance: epigenetic control of cellular quiescence by the tumor suppressor PRDM2/ $\mathrm{RIZ}$ at a bivalent domain in the cyclin a gene. Nucleic Acids Res. Internet]. 2015 [cited 2018 Nov 4];43:6236-6256. Available from: http://www.ncbi.nlm.nih.gov/pubmed/26040698

57. Recouvreux MV, Camilletti MA, Rifkin DB, et al. The pituitary TGF $\beta 1$ system as a novel target for the treatment of resistant prolactinomas. J Endocrinol. 2016;228:R73-R83.

58. Massagué J. TGF-beta signal transduction. Annu Rev Biochem. 1998;67:753-791.

59. Heldin C-H, Miyazono K, Ten Dijke P. TGF- $\beta$ signalling from cell membrane to nucleus through SMAD proteins. Nature. 1997;390:465-471.

60. Sarkar DK, Kim KH, Minami S. Transforming growth factor-beta 1 messenger RNA and protein expression in the pituitary gland: its action on prolactin secretion and lactotropic growth. Mol Endocrinol. 1992;6:1825-1833.

61. Recouvreux MV, Guida MC, Rifkin DB, et al. Active and total transforming growth factor- $\beta 1$ are differentially regulated by dopamine and estradiol in the pituitary. Endocrinology. 2011;152:2722-2730.

62. Li Z, Liu Q, Li C, et al. The role of TGF- $\beta / S m a d$ signaling in dopamine agonist-resistant prolactinomas. Mol Cell Endocrinol. 2015;402:64-71.

63. Marini F, Falchetti A, Monte F, et al. Multiple endocrine neoplasia type 1. Orphanet J Rare Dis. Internet]. 2006 [cited 2018 Nov 5];1:38. Available from: http://www.ncbi.nlm.nih.gov/pubmed/17014705

64. Vergès $B$, Boureille $F$, Goudet $P$, et al. Pituitary disease in men type 1 (MEN1): data from the France-Belgium MEN1 multicenter study. J Clin Endocrinol Metab. 2002;87:457-465.

65. Trouillas J, Labat-Moleur F, Sturm N, et al. Pituitary tumors and hyperplasia in multiple endocrine neoplasia type 1 syndrome (MEN1): A case-control study in a series of 77 patients versus 2509 non-MEN1 patients. Am J Surg Pathol. 2008;32:534-543.

66. Delemer B. MEN1 and pituitary adenomas. Ann Endocrinol (Paris). 2012;73:59-61.

67. Subasinghe $\mathrm{CJ}$, Somasundaram N, Sivatharshya P, et al. Giant prolactinoma of young onset: a clue to diagnosis of MEN-1 syndrome. 
Case Rep Endocrinol. Internet]. 2018 [cited 2018 Nov 4];2018:1-6. Available from: http://www.ncbi.nlm.nih.gov/pubmed/30186640

68. Beckers A, Aaltonen LA, Daly AF, et al. familial isolated pituitary adenomas (FIPA) and the pituitary adenoma predisposition due to mutations in the aryl hydrocarbon receptor interacting protein (AIP) gene. Endocr Rev. Internet]. 2013 [cited 2018 Nov 21];34:239-277. Available from: http://www.ncbi.nlm.nih.gov/pubmed/23371967

69. Peverelli E, Mantovani G, Vitali E, et al. Filamin-A is essential for dopamine D2 receptor expression and signaling in tumorous lactotrophs. J Clin Endocrinol Metab. 2012;97:967-977.

70. Wang F, Gao H, Li C, et al. Low levels of PRB3 mRNA are associated with dopamine-agonist resistance and tumor recurrence in prolactinomas. J Neurooncol. 2014;116:83-88.

71. Huang HY, Zhai $W$, Tang $\mathrm{H}$, et al. Cabergoline for the treatment of bromocriptine-resistant invasive giant prolactinomas. Endocrine. Internet]. 2018 [cited 2019 Jan 20];62:464-469. Available from: http://www.ncbi.nlm.nih.gov/pubmed/30238326

72. Dos Santos Nunes V, El Dib R, Boguszewski CL, et al. Cabergoline versus bromocriptine in the treatment of hyperprolactinemia: a systematic review of randomized controlled trials and meta-analysis. Pituitary. Internet]. 2011 [cited 2018 Nov 4];14:259-265. Available from: http:// www.ncbi.nlm.nih.gov/pubmed/21221817

73. Delgrange $E$, Maiter $D$, Donckier J. Effects of the dopamine agonist cabergoline in patients with prolactinoma intolerant or resistant to bromocriptine. Eur J Endocrinol. Internet]. 1996 [cited 2019 Jan 20];134:454-456. Available from: http://www.ncbi.nlm.nih.gov/ pubmed/8640297

74. Colao A, Di Sarno A, Sarnacchiaro F, et al. Prolactinomas resistant to standard dopamine agonists respond to chronic cabergoline treatment. J Clin Endocrinol Metab. Internet]. 1997 [cited 2019 Jan 21];82:876-883. Available from: http://www.ncbi.nlm.nih.gov/ pubmed/9062500

75. Gillam MP, Middler S, Freed DJ, et al. The novel use of very high doses of cabergoline and a combination of testosterone and an aromatase inhibitor in the treatment of a giant prolactinoma. J Clin Endocrinol Metab. Internet]. [cited 2019 Jan 20];87:4447-4451. Available from: https://academic.oup.com/jcem/article-lookup/doi/ 10.1210/jc.2002-020426

76. Iyer $\mathrm{P}$, Molitch $\mathrm{M}$. positive prolactin response to bromocriptine in 2 patients with cabergoline-resistant prolactinomas. Endocr Pract. Internet]. 2011 [cited 2019 Jan 20];17:e55-e58. Available from: http://www.ncbi.nlm.nih.gov/pubmed/21324816

77. Kreutzer J, Buslei $R$, Wallaschofski $H$, et al. Operative treatment of prolactinomas: indications and results in a current consecutive series of 212 patients. Eur J Endocrinol. 2008;158:11-18.

78. Shimon I, Sosa E, Mendoza V, et al. Giant prolactinomas larger than $60 \mathrm{~mm}$ in size: a cohort of massive and aggressive prolactin-secreting pituitary adenomas. Pituitary. 2016;19:429-436. Internet]. Available from: http://link.springer.com/10.1007/s11102-016-0723-4

79. Shimon I, Benbassat C, Hadani M. Effectiveness of long-term cabergoline treatment for giant prolactinoma: study of 12 men. Eur J Endocrinol. Internet]. 2007 [cited 2019 Jan 7];156:225-231. Available from: https:// eje.bioscientifica.com/view/journals/eje/156/2/1560225.xml

80. Corsello SM, Ubertini G, Altomare $M$, et al. Giant prolactinomas in men: efficacy of cabergoline treatment. Clin Endocrinol (Oxf). 2003;58:662-670.

81. Hamilton DK, Vance ML, Boulos PT, et al. Surgical outcomes in hyporesponsive prolactinomas: analysis of patients with resistance or intolerance to dopamine agonists. Pituitary. 2005;8:53-60.

82. Dallapiazza RF, Jane JA. Outcomes of endoscopic transsphenoidal pituitary surgery. Endocrinol Metab Clin North Am. 2015;44:105-115.

83. Jan $M$, Dufour $H$, Brue $T$, et al. Prolactinoma surgery. Ann Endocrinol (Paris). 2007;68:118-119.

84. Song Y-J, Chen M-T, Lian W, et al. Surgical treatment for male prolactinoma. Medicine (Baltimore). 2017;96:e5833.

85. Primeau V, Raftopoulos C, Maiter D. Outcomes of transsphenoidal surgery in prolactinomas: improvement of hormonal control in dopamine agonist-resistant patients. Eur J Endocrinol. 2012;166:779-786.

\section{- One study describing the outcome of surgery in DA-resistant} prolactinomas.

86. Donegan D, Atkinson JLD, Jentoft M, et al. Surgical outcomes of prolactinomas in recent era: results of a heterogenous group. Endocr Pract. 2017;23:37-45.

87. Castinetti F, Régis J, Dufour $\mathrm{H}$, et al. Role of stereotactic radiosurgery in the management of pituitary adenomas. Nat Rev Endocrinol. 2010;6:214-223.

88. Castinetti F, Nagai M, Morange I, et al. Long-term results of stereotactic radiosurgery in secretory pituitary adenomas. J Clin Endocrinol Metab. 2009;94:3400-3407.

89. Pouratian N, Sheehan J, Jagannathan J, et al. gamma knife radiosurgery for medically and surgically refractory prolactinomas. Neurosurgery. 2006;59:255-266.

90. Ježková J, Hána V, Kršek M, et al. Use of the Leksell gamma knife in the treatment of prolactinoma patients. Clin Endocrinol (Oxf). 2009;70:732-741.

91. Tanaka S, Link MJ, Brown PD, et al. gamma knife radiosurgery for patients with prolactin-secreting pituitary adenomas. World Neurosurg. Internet]. 2010 [cited 2019 Jan 8];74:147-152. Available from: https://linkinghub.elsevier.com/retrieve/pii/ S1878875010002020

92. Cohen-Inbar O, Xu Z, Schlesinger D, et al. Gamma knife radiosurgery for medically and surgically refractory prolactinomas: long-term results. Pituitary. 2015;18:820-830.

93. Castinetti F, Brue T. Gamma knife radiosurgery in pituitary adenomas: why, who, and how to treat? Discov Med. 2010;10:107-111.

94. Regis J, Castinetti F. Radiosurgery: a useful first-line treatment of prolactinomas? World Neurosurg. 2010;74:103-104.

95. Stupp R, Mason WP, van Den Bent MJ, et al. Radiotherapy plus concomitant and adjuvant temozolomide for glioblastoma. N Engl J Med. Internet]. 2005 [cited 2018 Nov 6];352:987-996. Available from: http://www.ncbi.nlm.nih.gov/pubmed/15758009

96. Zhang J, Stevens MFG, Bradshaw TD. Temozolomide: mechanisms of action, repair and resistance. Curr Mol Pharmacol. Internet]. [cited 2019 Jan 22];5:102-114. Available from: http://www.ncbi. nlm.nih.gov/pubmed/22122467

97. Hegi ME, Diserens A-C, Gorlia T, et al. MGMT gene silencing and benefit from temozolomide in glioblastoma. N Engl J Med. Internet]. 2005 [cited 2019 Jan 16];352:997-1003. Available from: http://www.ncbi.nlm.nih.gov/pubmed/15758010

98. Lim S, Shahinian H, Maya MM, et al. Temozolomide: a novel treatment for pituitary carcinoma. Lancet Oncol. 2006;7:518-520.

99. Raverot G, Sturm N, De Fraipont F, et al. Temozolomide treatment in aggressive pituitary tumors and pituitary carcinomas: A French multicenter experience. J Clin Endocrinol Metab. 2010.

- The first study dealing with the use of temozolomide in aggressive pituitary tumors.

100. Raverot G, Castinetti F, Jouanneau E, et al. Pituitary carcinomas and aggressive pituitary tumours: merits and pitfalls of temozolomide treatment. Clin Endocrinol (Oxf). 2012;76:769-775.

101. Lasolle H, Cortet $\mathrm{C}$, Castinetti $\mathrm{F}$, et al. Temozolomide treatment can improve overall survival in aggressive pituitary tumors and pituitary carcinomas. Eur J Endocrinol. 2017;176:769-777.

102. Philippon M, Morange I, Barrie $M$, et al. Long-term control of a MEN1 prolactin secreting pituitary carcinoma after temozolomide treatment. Ann Endocrinol (Paris). Internet]. 2012 [cited 2018 Nov 7];73:225-229. Available from: http://www.ncbi.nlm.nih.gov/ pubmed/22520146

103. Raverot G, Burman P, McCormack A, et al. European society of endocrinology clinical practice guidelines for the management of aggressive pituitary tumours and carcinomas. Eur J Endocrinol. 2018;178:G1-G24.

104. Fusco A, Gunz $G$, Jaquet $P$, et al. Somatostatinergic ligands in dopamine-sensitive and -resistant prolactinomas. Eur J Endocrinol. 2008;158:595-603.

105. Fusco A, Lugli F, Sacco E, et al. Efficacy of the combined cabergoline and octreotide treatment in a case of a dopamine-agonist resistant macroprolactinoma. Pituitary. 2011;14:351-357. 
106. Sosa-Eroza E, Espinosa E, Ramírez-Rentería C, et al. Treatment of multiresistant prolactinomas with a combination of cabergoline and octreotide LAR. Endocrine. Internet]. 2018 [cited 2018 Nov 4];61:343-348. Available from: http://www.ncbi.nlm.nih.gov/ pubmed/29948930

107. Cuny T, Mohamed A, Graillon T, et al. Somatostatin receptor sst2 gene transfer in human prolactinomas in vitro: impact on sensitivity to dopamine, somatostatin and dopastatin, in the control of prolactin secretion. Mol Cell Endocrinol. 2012;355:106-113.

108. Gadelha MR, Bronstein MD, Brue T, et al. Pasireotide versus continued treatment with octreotide or lanreotide in patients with inadequately controlled acromegaly (PAOLA): a randomised, phase 3 trial. Lancet Diabetes Endocrinol. 2014;2:875-884.

109. Hofland L, van der Hoek J, van Koetsveld PM, et al. The novel somatostatin analog SOM230 is a potent inhibitor of hormone release by growth hormone- and prolactin-secreting pituitary adenomas in vitro. J Clin Endocrinol Metab. 2004;89:1577-1585.

110. Fedele M, De Martino I, Pivonello R, et al. SOM230, a new somatostatin analogue, is highly effective in the therapy of growth hormone/prolactin-secreting pituitary adenomas. Clin Cancer Res. 2007;13:2738-2744.

111. Lasolle H, Vasiljevic A, Borson-Chazot F, et al. Pasireotide: a potential therapeutic alternative for resistant prolactinoma. Ann Endocrinol (Paris). Internet]. 2018 [cited 2018 Nov 1]; Available from: http://www.ncbi.nlm.nih.gov/pubmed/30318256

112. Baldari $S$, Ferraù $F$, Alafaci $C$, et al. First demonstration of the effectiveness of peptide receptor radionuclide therapy (PRRT) with $111 \mathrm{ln}$-DTPA-octreotide in a giant PRL-secreting pituitary adenoma resistant to conventional treatment. Pituitary. Internet]. 2012 [cited 2018 Nov 9];15 Suppl 1: S57-60. Available from: http://link. springer.com/10.1007/s11102-011-0373-5

113. Strosberg J, El-Haddad G, Wolin E, et al. Phase 3 trial of ${ }^{177}$ Lu-Dotatate for midgut neuroendocrine tumors. N Engl J Med. Internet]. 2017 [cited 2018 Jul 14];376:125-135. Available from: http://www.ncbi.nlm.nih.gov/pubmed/28076709

114. Liu X, Liu Y, Gao J, et al. Combination treatment with bromocriptine and metformin in patients with bromocriptine-resistant prolactinomas: pilot study. World Neurosurg. 2018;115:94-98.

115. Gao J, Liu Y, Han G, et al. Metformin inhibits growth and prolactin secretion of pituitary prolactinoma cells and xenografts. J Cell Mol Med. Internet]. 2018 [cited 2018 Nov 4]; 22:6368-6379. Available from: http://www.ncbi.nlm.nih.gov/pubmed/30334324

116. Esparís-Ogando A, Montero JC, Arribas J, et al. Targeting the EGF/ HER ligand-receptor system in cancer. Curr Pharm Des. Internet]. 2016 [cited 2018 Nov 6];22:5887-5898. Available from: http://www. ncbi.nlm.nih.gov/pubmed/27426127

117. Kontogeorgos G, Stefaneanu L, Kovacs K, et al. Localization of epidermal growth factor (EGF) and epidermal growth factor receptor (EGFr) in human pituitary adenomas and nontumorous pituitaries: an immunocytochemical study. Endocr Pathol. 1996;7:63-70.

118. Cooper O, Mamelak A, Bannykh S, et al. Prolactinoma ErbB receptor expression and targeted therapy for aggressive tumors. Endocrine. 2014;46:318-327.

119. Cooper O, Vlotides G, Fukuoka H, et al. Expression and function of ErbB receptors and ligands in the pituitary. Endocr Relat Cancer. 2011;18:R197-R211.

120. Vlotides G, Siegel E, Donangelo I, et al. Rat prolactinoma cell growth regulation by epidermal growth factor receptor ligands. Cancer Res. 2008;68:6377-6386.
121. Saxton RA, Sabatini DM. mTOR signaling in growth, metabolism, and disease. Cell. 2017;168:960-976.

122. Dworakowska $D$, Wlodek $E$, Leontiou $C A$, et al. Activation of RAF/ MEK/ERK and PI3K/AKT/mTOR pathways in pituitary adenomas and their effects on downstream effectors. Endocr Relat Cancer. 2009;16:1329-1338.

123. Roof AK, Jirawatnotai S, Trudeau T, et al. The balance of PI3K and ERK signaling is dysregulated in prolactinoma and modulated by dopamine. Endocrinology. 2018;159:2421-2434.

124. Chen R, Duan J, Li L, et al. MTOR promotes pituitary tumor development through activation of PTTG1. Oncogene. 2017;36:979.

125. Geng X, Ma L, Li $Z$, et al. Bromocriptine induces autophagy-dependent cell death in pituitary adenomas. World Neurosurg. 2017;100:407-416.

126. Zhang $D$, Way JS, Zhang $X$, et al. Effect of everolimus in treatment of aggressive prolactin-secreting pituitary adenomas. J Clin Endocrinol Metab. Internet]. 2019 [cited 2019 Jan 20]; Available from: https://academic.oup.com/jcem/advance-article/doi/10.1210/ jc.2018-02461/5273783

127. Smith TR, Hulou MM, Huang KT, et al. Current indications for the surgical treatment of prolactinomas. J Clin Neurosci. Internet]. 2015 [cited 2018 Nov 4];22:1785-1791. Available from: http://www.ncbi. nlm.nih.gov/pubmed/26277642

128. Caputo C, Prior D, Inder WJ. The need for annual echocardiography to detect cabergoline-associated valvulopathy in patients with prolactinoma: a systematic review and additional clinical data. Lancet Diabetes Endocrinol. 2015;3:906-913.

129. Trouillas J, Roy P, Sturm N, et al. A new prognostic clinicopathological classification of pituitary adenomas: a multicentric case-control study of 410 patients with 8 years post-operative follow-up. Acta Neuropathol. Internet]. 2013 [cited 2019 Mar 9];126:123-135. Available from: http://www.ncbi.nlm.nih.gov/pubmed/23400299

130. Eroukhmanoff J, Tejedor I, Potorac I, et al. MRI follow-up is unnecessary in patients with macroprolactinomas and long-term normal prolactin levels on dopamine agonist treatment. Eur J Endocrinol. 2017;176:123-132.

131. Lin AL, Jonsson P, Tabar V, et al. Marked response of a hypermutated ACTH-secreting pituitary carcinoma to ipilimumab and nivolumab. J Clin Endocrinol Metab. Internet]. 2018 [cited 2019 Jan 23];103:3925-3930. Available from: http://www.ncbi.nlm.nih. gov/pubmed/30085142

132. Colao A, Di Sarno A, Landi ML, et al. Long-term and low-dose treatment with cabergoline induces macroprolactinoma shrinkage. J Clin Endocrinol Metab. 1997;82:3574-3579.

133. Ferrari $\mathrm{Cl}$, Abs R, Bevan JS, et al. Treatment of macroprolactinoma with cabergoline: a study of 85 patients. Clin Endocrinol (Oxf). 1997;46:409-413.

134. Espinosa E, Sosa E, Mendoza V, et al. Giant prolactinomas: are they really different from ordinary macroprolactinomas? Endocrine. 2016;52:652-659.

135. Green Al, Sherlock M, Stewart PM, et al. Extensive experience in the management of macroprolactinomas. Clin Endocrinol (Oxf). 2014;81:85-92.

136. Wu ZR, Zhang Y, Cai L, et al. Long-term clinical outcomes of invasive giant prolactinomas after a mean ten-year followup. Int J Endocrinol. 2016;2016:1-7.

137. Rohmer V, Freneau E, Morange I, et al. Efficacy of quinagolide in resistance to dopamine agonists: results of a multicenter study. club de l'Hypophyse. Ann d Endocrinol. 2000;61:411-417. 